\title{
O ENSINO ACADÊMICO DA ETNOBOTÂNICA NO BRASIL ${ }^{1}$
}

\author{
Viviane Stern da Fonseca-Kruel ${ }^{2}$, Inês Machline Silva ${ }^{3}$ \\ \& Cláudio Urbano B. Pinheiro ${ }^{4}$
}

\begin{abstract}
RESUMO
(O ensino acadêmico da etnobotânica nas universidades do Brasil) A etnobotânica vem sendo definida como o estudo das sociedades humanas em suas relações com as plantas. É uma disciplina antiga em sua prática, mas jovem em sua teoria. A pesquisa etnobotânica cresceu na última década, especialmente na América Latina. Esse crescimento exigiu o entendimento da disciplina na sua diversidade teórico-metodológica, consequiência do seu caráter interdisciplinar e necessidade da sistematização da mesma. Este trabalho buscou resgatar e avaliar o ensino formal da etnobotânica em instituições brasileiras, a partir de questionários enviados a Instituições de ensino e pesquisa no país. Utilizou-se ainda a via eletrônica para atualizações referentes aos cursos de graduações. Foram encontradas 13 instituições que oferecem etnobotânica como disciplina específica, e 27 instituições, em que a etnobotânica não é oferecida formalmente, sendo abordada apenas como tópico, principalmente relacionada aos cursos da área de Ciências Biológicas. Tanto os cursos com disciplinas específicas quanto aqueles em que consta como tópico, concentram-se nas instituições das Regiões Sudeste (51\%) e Nordeste (31\%). Otrabalho incluiu também uma avaliação dos conteúdos programáticos das disciplinas e bibliografias utilizadas. Os dados mostraram uma tendência de crescimento do ensino formal da etnobotânica tanto na graduação quanto na pós-graduação no Brasil.
\end{abstract}

Palavras-chave: Etnobotânica, Brasil, instituições de ensino.

\section{Abstract}

(Ethnobotany academic teaching in Brazilian Universities) Ethnobotany is the study of human societies and their relationship with plants. It is an old discipline in practice, but young in theory. Ethnobotanical research has grown perceptibly in the past decade in many parts of the world, especially in Latin America. This growth calls for a broader understanding of the discipline in all its theoretical and methodological diversity. The interdisciplinary nature of ethnobotany also requires a greater academic systematization. This study focuses on the assessment of formal teaching methods of ethnobotany in Brazilian universities. Data were gathered from questionnaires sent over the Internet and filled out by graduate-course coordinators in Brazil, and by members of the Brazilian Ethnobotanical Committee of the Botanical Society of Brazil, and of the Brazilian Society of Ethnobiology and Ethnoecology. Thirteen Brazilian universities offer Ethnobotany as a specific discipline and in 27 other institutions, Ethnobotany is included as a topic in other disciplines. In both cases, these courses are generally offered by universities in Northeastern and Southeastern Brazil. The study included an evaluation of the contents as well as of references used in the courses. The data showed a strong tendency for growth of formal teaching of Ethnobotany in Brasil at both the undergraduate and graduate levels.

Key-words: Teaching of ethnobotany, university level, Brazil.

\section{INTRODUÇÃo}

O Brasil é um dos países de maior diversidade biológica e apresenta alguns dos biomas mais ricos do mundo, como a amazônia, o pantanal, a mata atlântica e o cerrado (Brasil 1998). Somada à diversidade biológica, $\mathrm{o}$ Brasil possui grande diversidade cultural, com cerca de 218 povos indígenas, além de numerosos povos não-indígenas (Diegues \& Arruda 2001). Estes grupos sociais possuem vasto conhecimento tradicional sobre as diferentes formas de aproveitamento e manejo dos recursos naturais, principalmente sobre as espécies vegetais.

Artigo recebido em 11/2004. Aceito para publicação em 03/2005.

${ }^{1}$ Documento apresentado no Taller Latinoamericano Desarrollo Curricular de Etnobotánica, fevereiro/2002, República Dominicana. Apoio financeiro do World Wide Fund for Nature (WWF/People and Plants) e do Grupo Etnobotánico Latinoamericano (GELA).

${ }^{2}$ Instituto dePesquisa Jardim Botânico do Rio de Janeiro. R. Pacheco Leão 915, JardimBotânico. Rio de Janeiro, Brasil. CEP: 22460-030. vfonseca@jbri.gov.br

${ }^{3}$ Universidade Federal Rural do Rio de Janeiro, Instituto de Biologia, Depto. Botânica. BR 467, km 7. Seropédica, RJ, Brasil. CEP23890-000. machline@ufrri.br

${ }^{4}$ Universidade Federal do Maranhão, Departamento de Oceanografia e Limnologia, Avenida dos Portugueses, s/n, Campus do Bacanga, CEP 65085-580, São Luis, MA. cpinheiro@elo.com.br 
Na atualidade, a etnobotânica é uma disciplina chave já que constitui uma ponte entre o saber popular e o científico estimulando o resgate do conhecimento tradicional, a conservação dos recursos vegetais e o desenvolvimento sustentável, especialmente nos países tropicais e subtropicais, onde as populações rurais dependem em parte das plantas e seus produtos para sua subsistência (Hamilton et al. 2003).

A etnobotânica tem sido definida como "o estudo das inter-relações diretas entre seres humanos e plantas" (Ford 1978). Esta disciplina abrange o estudo das interrelações das sociedades humanas com a natureza (Alcorn 1995; Alexiades \& Sheldon 1996), pois seu caráter interdisciplinar e integrador é demonstrado nadiversidade de tópicos que pode estudar, como por exemplo, os fatores culturais, sociais, políticos, biológicos, econômicos e ecológicos que determinam se uma planta é percebida como um recurso; como é distribuído o conhecimento etnobotânico entre as populações humanas locais; como as pessoas diferenciam e classificam os elementos vegetais nos seus ambientes naturais e, até que ponto as decisões tomadas sobre o uso e manejo dos recursos vegetais são adaptativos (Alcorn 1995).

Trata-se de uma disciplina científica relativamente nova que não tem sido sistematizada e formalizada como as ciências já estabelecidas (Hamilton et al. 2003). Entretanto, tem sido reconhecida por muitos cientistas que valorizam e a reconhecem como tendo um papel relevante no desenvolvimento dos povos (Hamilton et al. 2003). Na realidade, pode-se dizer que a etnobotânica é antiga em sua prática, mas jovem em sua teoria, já que ela não é tão recente quanto se pensa, pois diferentes estudos demonstram que sua história remonta às relações entre os seres humanos $\mathrm{e}$ as plantas, aos domínios da botânica aplicada e da etnografia botânica (Balick \& Cox 1996; Hamilton et al. 2003).

A pesquisa etnobotânica cresceu visivelmente na última década em muitas partes do mundo, em especial na América Latina, e particularmente em países como o
México, a Colômbia e o Brasil (Hamilton et al. 2003). O artigo de Alfaro (1994) ilustra o interesse que o tema vem despertando na comunidade científica latino-americana, embora $52 \%$ das publicações em periódicos internacionais foram desenvolvidos na América Latina por pesquisadores norteamericanos, ingleses e franceses. Neste levantamento a América do Sul havia produzido $41 \%$ dos estudos de toda a América Latina, sendo que a maior parte deles foram desenvolvidos por pesquisadores nacionais dos seguintes países: Uruguai (100\%), Argentina (90\%), Chile (78\%), Brasil (67\%) e Paraguai $(61 \%)$.

No Brasil, o número de instituições e pesquisadores que desenvolvem estudos etnobotânicos cresceu exponencialmente. Os trabalhos desenvolvidos pela Comissão de Etnobotânica da Sociedade Botânica do Brasil (CEB/SBB) e também pela Sociedade Brasileira de Etnobiologia e Etnoecologia (SBEE), mostraram-se fundamentais no sentido de organizar e estimular a realização de diferentes fóruns para debates durante seus eventos. Desde então a etnobotânica vem tendo maior visibilidade e impulso no país, como demonstram os mais de 500 estudos sobre diferentes tópicos nesta área nos últimos congressos nacionais de botânica. Tal crescimento exigiu o entendimento da disciplina na sua diversidade teórico-metodológica, consequiência do seu caráter inter-, multi- e intradisciplinar, e a necessidade de sua sistematização nos cursos de graduação e de pós-graduação, especialmente no Brasil. No entanto, poucas instituições já inseriram em suas grades curriculares na graduação e/ou pós-graduação, disciplinas ou cursos específicos relacionados às Etnociências.

Dentro deste quadro, este trabalho buscou o resgate e a avaliação crítica do ensino formal da etnobotânica em instituições de ensino brasileiras para servir de base a reflexões e considerações sobre a formação de profissionais qualificados nesse campo do saber. 


\section{Material e Métodos}

O World Wide Fund for Nature (WWF) por meio do Programa People and Plants, organizou em 2002, workshop na Etiópia, Kenya, Malásia, Paquistão, China, Tanzânia, Uganda e na Rebúplica Dominicana, este último com representantes de países da América Latina. Nestes eventos as informações regionais trazidas pelos etnobotânicos e educadores subsidiaram a elaboração do documento The Purposes and Teaching of Applied Ethnobotany (Hamilton et al. 2003). Parte dos dados, aqui organizados, foram apresentados durante o Taller Latinoamericano de Desarrollo Curricular de Etnobotánica (fevereiro de 2002) na República Dominicana. Naquela ocasião, discutiu-se a situação do ensino da etnobotânica no Brasil, nas instituições de nível superior, públicas e privadas e institutos de pesquisas brasileiros, bem como de outros países latino-americanos.

Para o levantamento dos dados foram enviadas questões padronizadas, na forma de tópicos, a serem respondidas pelos Coordenadores dos cursos de pós-graduação no Brasil. As questões encaminhadas foram: a) a disciplina específica de etnobotânica é ministrada em sua instituição? ela é contemplada na graduação, pós-graduação ou como curso de extensão? b) a etnobotânica está relacionada a um determinado curso e/ou departamento? qual? c) qual o programa, ementa, conteúdo, horas/aula? d) conhece outra instituição brasileira que apresenta a área de etnobotânica? qual? e) quais são as necessidades enfrentadas pelos docentes (no Brasil) na área de etnobotânica?

Para complementação das informações foram também enviados formulários à pesquisadores e/ou docentes vinculados à Comissão de Etnobotânica da Sociedade Botânica do Brasil (CEB/SBB), bem como à Sociedade Brasileira de Etnobiologia e Etnoecologia (SBEE).

Os dados obtidos foram atualizados e complementados nos anos de 2004 e início de 2005, a partir de consultas a Internet, em portais de instituições brasileiras que apresentam cursos com perfil relacionado ao ensino de etnobotânica, em nível de graduação reconhecidos pelo Ministério da Educação (MEC) e de pós-graduação (sensu strictu), credenciados junto a Fundação Coordenação de Aperfeiçoamento de Pessoal de Nível Superior (CAPES 2003).

\section{Resultados e Discussão}

O Instituto Nacional de Estudos e Pesquisas Educacionais Anísio Teixeira - INEP (Censo 2003) registra que, das 1.859 instituições de ensino superior no Brasil, 207 são públicas $(11,1 \%)$ e 1.652 privadas $(88,9 \%)$. Segundo a Secretaria de Ensino Superior do Ministério da Educação, o Brasil conta com 43 Universidades Federais e 78 Universidades Estaduais, distribuídas pelos 27 estados brasileiros (MEC 2003; IBGE 2001), além de muitas instituições privadas. São registrados pelo MEC 16.453 cursos de graduação, dos quais $10.847(65,6 \%)$ estão no setor privado e $5.662(34,4 \%)$ em instituições públicas (INEP - Censo 2003).

Os cursos de pós-graduação no Brasil vêm sendo divididos pela CAPES (2003), em nove grandes áreas do conhecimento. Verificou-se que a etnobotânica é inserida em cursos de pós-graduação nas grandes áreas de Ciências Agrárias, Ciências Biológicas, Ciências da Saúde e ainda uma grande área denominada "Outras" aonde se encontram programas com caráter multidisciplinar, como: Desenvolvimento e Meio Ambiente, Agroecossistemas, Agroecologia, Ciências Ambientais e Desenvolvimento Sustentável do Trópico Úmido, entre outros.

A partir do levantamento observou-se que em apenas treze instituições brasileiras a etnobotânica vem sendo oferecida como disciplina específica, já implementada ou em fase de implementação. Em oito destas instituições a etnobotânica encontra-se em nível de graduação e em nove em nível de pós-graduação.

Em dez instituições a etnobotânica está ligada à área de Ciências Biológicas (cinco disciplinas são oferecidas na graduação e sete 
na pós-graduação). Na Universidade Federal da Paraíba (UFPB) e na Universidade Estadual de Campinas (Unicamp) a disciplina é oferecida nos cursos de graduação em Ciências Farmacêuticas. Na Universidade Estadual Paulista (UNESP/Botucatu) a área de Ciências Agrárias oferece a disciplina na graduação e na Pós-graduação. Já a Universidade de Brasília tem a etnobotânica em nível de pósgraduação, na área de Ciências Florestais (Tabela 1).

Ressalta-se que nas Universidades Federal de Pernambuco (UFPE) e Universidade Estadual Paulista (UNESP de Rio Claro e Botucatu) a etnobotânica está contemplada em mais de uma disciplina. A UNESP - Faculdade de Ciências Agronômicas (Botucatu, São Paulo), além destes cursos, oferece também Cursos de Extensão Universitária, com sistema de créditos para alunos de pós-graduação. Esta iniciativa é mais uma estratégia que vem permitindo a vinda de professores convidados, ampliando o acesso dos alunos a diferentes enfoques na área.

A etnobotânica concentra-se em instituições das Regiões Sudeste e Nordeste do Brasil com 51 e $31 \%$ das disciplinas oferecidas, respectivamente. Provavelmente, tal concentração se dá em consequiência da grande concentração de Universidades e de docentes e/ou pesquisadores.

Ainda a partir do levantamento elaborado verificou-se que em 27 instituições de ensino, a etnobotânica não é oferecida formalmente, porém é abordada em diversas disciplinas, tanto em nível de graduação quanto de pósgraduação, oferecidas principalmente nas grandes áreas de Ciências Biológicas (19), Ciências Farmacêuticas (5) e Ciências Agrárias (5) (Tabela 2).

Os programas referentes à disciplina específica de etnobotânica, tanto na graduação como na pós-graduação, apresentam em comum uma combinação de teoria e prática, motivando os alunos com leituras, aulas práticas, elaboração de seminários e levantamentos bibliográficos.
A carga horária da disciplina varia na graduação entre 30 e 60 horas e na Pósgraduação entre 45 e 120 horas. O número de créditos obtidos pelos alunos varia em função desta carga horária (Tabela 1).

Como pré-requisito para os alunos de graduação cursarem etnobotânica é exigido, em geral, que estes tenham cursado disciplinas relacionadas à Sistemática Vegetal. Nos programas analisados os objetivos a serem alcançados são:

1. Estimular o desenvolvimento de pesquisas nas áreas de etnobotânica e Botânica Econômica.

2. Proporcionar uma visão geral do uso, domesticação e evolução das plantas ao longo da história do ser humano na Terra.

3. Fornecer subsídios teóricos e práticos para o conhecimento, compreensão e interpretação do significado cultural, manejo e usos tradicionais dos elementos da flora.

4. Introduzir os princípios básicos da etnobotânica e da Botânica Econômica e sua aplicação no desenvolvimento regional.

5. Fornecer subsídios para o conhecimento dos grandes grupos vegetais de interesse econômico.

6. Indicar meios de resgate e utilização do conhecimento tradicional dos recursos vegetais.

7. Mostrar os métodos de coleta, processamento e análise de dados etnobotânicos e sua aplicação em programas de desenvolvimento sustentável e conservação.

8. Estudar os grandes ecossistemas do Brasil sob a ótica do uso de seus recursos vegetais, seu manejo, estado de conservação e relação com as populações que os exploram.

A análise dos conteúdos programáticos das disciplinas nas instituições de ensino revelou aspectos comuns com relação à abordagem conceitual da etnobotânica, inserindo temas atuais, como a prospecção da biodiversidade, o desenvolvimento de novos produtos, a conservação da natureza e o uso sustentável dos recursos vegetais. Entretanto, 
Tabela 1: Instituições de ensino superior no Brasil que apresentam a etnobotânica como disciplina específica na grade curricular, implementadas ou em fase de implementação, na graduação e pósgraduação.

\begin{tabular}{|c|c|c|c|c|c|c|}
\hline Disciplina & Nível & $\begin{array}{r}\text { Ár } \\
\text { conh }\end{array}$ & $\begin{array}{l}\text { Área do } \\
\text { nhecimento }\end{array}$ & Instituição & Região & $\begin{array}{l}\text { Carga } \\
\text { horária }\end{array}$ \\
\hline $\begin{array}{l}\text { Etnobotânica: } \\
\text { conceitos, métodos } \\
\text { e aplicações }\end{array}$ & $\mathrm{PG}(\mathrm{M})$ & Botânica & $\mathrm{CB}$ & $\begin{array}{l}\text { Universidade Federal Rural } \\
\text { da Amazônia (MPEG) }\end{array}$ & Norte & 45 \\
\hline Etnobotânica & PG $(M, D)$ & Botânica & $\mathrm{CB}$ & $\begin{array}{l}\text { Universidade Estadual de Feira } \\
\text { de Santana (UEFS/BA) }\end{array}$ & Nordeste & 60 \\
\hline $\begin{array}{l}\text { Taxonomia e } \\
\text { etnobotânica }\end{array}$ & G & Farmácia & $\mathrm{CF}$ & $\begin{array}{l}\text { Universidade Federal da Paraíba } \\
\text { (UFPB) }\end{array}$ & & 30 \\
\hline Etnobotânica & PG (M,D) & Botânica & $\mathrm{CB}$ & $\begin{array}{l}\text { Universidade Federal de } \\
\text { Pernambuco (UFPE) }\end{array}$ & & 60 \\
\hline $\begin{array}{l}\text { Princípios de } \\
\text { etnobotânica }\end{array}$ & G & Botânica & $\mathrm{CB}$ & $\begin{array}{l}\text { Universidade Federal de } \\
\text { Pernambuco (UFPE) }\end{array}$ & & 45 \\
\hline Etnobotânica & PG (M,D) & Botânica & $\mathrm{CB}$ & $\begin{array}{l}\text { Universidade Federal Rural } \\
\text { de Pernambuco (UFRPE) }\end{array}$ & & - \\
\hline $\begin{array}{l}\text { Etnobotânica do } \\
\text { Cerrado }\end{array}$ & G & Botânica & $\mathrm{CB}$ & Universidade de Brasília (UNB) & Centro-Oeste & $e-$ \\
\hline $\begin{array}{l}\text { Etnobotânica e } \\
\text { sócio florestas }\end{array}$ & PG(D) & $\begin{array}{l}\text { Conservação } \\
\text { da natureza }\end{array}$ & $\mathrm{CFl}$ & Universidade de Brasília (UNB) & Centro-Oeste & te - \\
\hline $\begin{array}{l}\text { Fundamentos em } \\
\text { etnobotânica }(*)\end{array}$ & G & $\begin{array}{l}\text { Agronomia/ } \\
\text { Produção vegetal } \\
\text { (Horticultura) }\end{array}$ & tal & $\begin{array}{l}\text { Universidade Estadual Paulista } \\
\text { (UNESP) - Faculdade de Ciências } \\
\text { Agronômicas (Botucatu/SP) }\end{array}$ & Sudeste & 30 \\
\hline Etnobotânica & PG $(M, D)$ & $\begin{array}{l}\text { Agronomia/ } \\
\text { Horticultura }\end{array}$ & CA & $\begin{array}{l}\text { Universidade Estadual Paulista } \\
\text { (UNESP) - Faculdade de Ciências } \\
\text { Agronômicas (Botucatu/SP) }\end{array}$ & Sudeste & 120 \\
\hline Etnobotânica & G & Ecologia & $\mathrm{CB}$ & $\begin{array}{l}\text { Universidade Estadual Paulista } \\
\text { (UNESP) - (Rio Claro/SP) }\end{array}$ & Sudeste & 60 \\
\hline Etnobotânica & PG & $\begin{array}{l}\text { Biologia } \\
\text { Vegetal; Ecologia }\end{array}$ & CB & $\begin{array}{l}\text { Universidade Estadual Paulista } \\
\text { (UNESP) - (Rio Claro/SP) }\end{array}$ & Sudeste & 120 \\
\hline $\begin{array}{l}\text { Etnobotânica de } \\
\text { plantas de interesse } \\
\text { farmacêutico }\end{array}$ & G & Farmácia & $\mathrm{CF}$ & $\begin{array}{l}\text { Universidade Estadual de } \\
\text { Campinas (UNICAMP) }\end{array}$ & Sudeste & - \\
\hline $\begin{array}{l}\text { Etnobotânica e } \\
\text { botânica econômica (* }\end{array}$ & *) & Botânica & $\mathrm{CB}$ & $\begin{array}{l}\text { Universidade Federal Rural do } \\
\text { Rio de Janeiro (UFRRJ) }\end{array}$ & Sudeste & 60 \\
\hline Etnobotânica & PG(M,D) & Botânica & $\mathrm{CB}$ & $\begin{array}{l}\text { Universidade Federal do Rio de } \\
\text { Janeiro (UFRJ/Museu Nacional) }\end{array}$ & Sudeste & 60 \\
\hline $\begin{array}{l}\text { Etnobotânica } \\
\text { (tópicos especiais*) }\end{array}$ & PG (M,D) & Botânica & $\mathrm{CB}$ & $\begin{array}{l}\text { Instituto de Pesquisas Jardim } \\
\text { Botânico do Rio de Janeiro - } \\
\text { Escola Nacional de Botânica } \\
\text { Tropical }\end{array}$ & Sudeste & 60 \\
\hline Etnobotânica $(*)$ & G & Botânica & $\mathrm{CB}$ & $\begin{array}{l}\text { Universidade do Vale do Rio dos } \\
\text { Sinos (Unisinos) }\end{array}$ & Sul & 60 \\
\hline
\end{tabular}

(CA) Ciências Agrárias; (CB) Ciências Biológicas; CF (Ciências Farmacêuticas); CFl (Ciências Florestais); (G) graduação; (PG) pós-graduação; (M) Mestrado; (D) Doutorado.
(-) Ausência de informação.
(*) Disciplinas propostas e em início de implementação 
Tabela 2: Instituições de ensino superior no Brasil que apresentam a etnobotânica incluída como tópico em disciplinas dos cursos de graduação ou pós-graduação.

\begin{tabular}{|c|c|c|c|c|c|}
\hline Disciplina & Nível & Curso & $\begin{array}{l}\text { rea do } \\
\text { hecimento }\end{array}$ & Instituição & Região \\
\hline Etnobiologia & G & Agronomia & $\mathrm{CA}$ & $\begin{array}{l}\text { UFAM - Faculdade } \\
\text { de Ciências Agrárias }\end{array}$ & Norte \\
\hline $\begin{array}{c}\text { Ecologia e manejo } \\
\text { de ecossistemas }\end{array}$ & PG(D) & $*$ & $\mathrm{CA}$ & NAEA/UFPA & Norte \\
\hline $\begin{array}{l}\text { Ecologia política } \\
\text { dos recursos florestais }\end{array}$ & PG(D) & $*$ & $\mathrm{CA}$ & NAEA/UFPA & Norte \\
\hline Etnobiologia $(*)$ & G & Biologia & $\mathrm{CB}$ & $\begin{array}{l}\text { UFPA } \\
\text { (Campus } \\
\text { Universitário } \\
\text { Santarém) }\end{array}$ & Norte \\
\hline $\begin{array}{l}\text { Etnobiologia; } \\
\text { botânica econômica }\end{array}$ & G & Biologia & $\mathrm{CB}$ & UEFS (BA) & Nordeste \\
\hline Botânica econômica & G & Biologia & $\mathrm{CB}$ & $\operatorname{UESC}(\mathrm{BA})$ & Nordeste \\
\hline $\begin{array}{l}\text { Farmacognosia I; } \\
\text { fitofármacos e fitoterápicos }\end{array}$ & G & Farmácia & $\begin{array}{l}\mathrm{CF} \\
\text { (Faculdad }\end{array}$ & $\begin{array}{l}\text { UFBA } \\
\text { de } \\
\text { Farmácia) }\end{array}$ & Nordeste \\
\hline $\begin{array}{l}\text { Farmacognosia; } \\
\text { curso de treinamento } \\
\text { do projeto Farmácias-Vivas }\end{array}$ & G & Farmácia & $\mathrm{CF}$ & $\begin{array}{l}\text { UFC - Laboratório } \\
\text { de Produtos Naturais }\end{array}$ & Nordeste \\
\hline Produtos naturais & PG (M) & $\begin{array}{l}\text { PG em Saúde } \\
\text { e Ambiente }\end{array}$ & CS & UFMA & Nordeste \\
\hline Etnobiologia & PG(M) & $\begin{array}{l}\text { Sustentabilidade } \\
\text { de Ecossistemas }\end{array}$ & $\mathrm{CB}$ & UFMA & Nordeste \\
\hline Etnoecologia & G & $\begin{array}{l}\text { Ciências } \\
\text { Aquáticas }\end{array}$ & CAq & UFMA & Nordeste \\
\hline Etnoecologia & G & Biologia & $\mathrm{CB}$ & UFRPE & Nordeste \\
\hline Sistemática vegetal & G & Biologia & $\mathrm{CB}$ & UFG & $\begin{array}{l}\text { Centro- } \\
\text { Oeste }\end{array}$ \\
\hline Botânica econômica & G & Biologia & $\mathrm{CB}$ & $\begin{array}{l}\text { UFG-Campus } \\
\text { Avançado de Jataí }\end{array}$ & $\begin{array}{l}\text { Centro- } \\
\text { Oeste }\end{array}$ \\
\hline Botânica econômica & $\mathrm{G}$ & Biologia & $\mathrm{CB}$ & $\mathrm{UnB}(\mathrm{DF})$ & $\begin{array}{l}\text { Centro- } \\
\text { Oeste }\end{array}$ \\
\hline $\begin{array}{l}\text { Plantas medicinais; } \\
\text { etnoecologia }\end{array}$ & PG (M) & $\begin{array}{l}\text { Ecologia e } \\
\text { Conservação da } \\
\text { Biodiversidade }\end{array}$ & $\mathrm{CB}$ & $\begin{array}{l}\text { UFMT - Instituto } \\
\text { de Biociências }\end{array}$ & $\begin{array}{l}\text { Centro- } \\
\text { Oeste }\end{array}$ \\
\hline Plantas medicinais & G & Agronomia & $\mathrm{CA}$ & $\begin{array}{l}\text { UFMS - Campus de } \\
\text { Dourados }\end{array}$ & $\begin{array}{l}\text { Centro- } \\
\text { Oeste }\end{array}$ \\
\hline Botânica econômica & G & Biologia & $\mathrm{CB}$ & UNICAMP & Sudeste \\
\hline Ecologia humana & PG & Ecologia & $\mathrm{CB}$ & $\begin{array}{l}\text { UNICAMP - Núcleo } \\
\text { de Estudos e Pesquisas } \\
\text { Ambientais (SP) }\end{array}$ & Sudeste \\
\hline $\begin{array}{l}\text { Recursos econômicos } \\
\text { vegetais; plantas medicinais } \\
\text { e tóxicas; ecologia humana }\end{array}$ & $\mathrm{G}$ & Biologia & $\mathrm{CB}$ & USP & Sudeste \\
\hline
\end{tabular}




\begin{tabular}{|c|c|c|c|c|c|}
\hline Disciplina & Nível & Curso & $\begin{array}{c}\text { Área do } \\
\text { conhecimento }\end{array}$ & Instituição & Região \\
\hline Botânica econômica & G & Biologia & $\mathrm{CB}$ & UNESP (Rio Claro/SP) & Sudeste \\
\hline $\begin{array}{l}\text { Plantas hortícolas } \\
\text { medicinais }\end{array}$ & $\mathrm{G}$ & Agronomia & $\mathrm{CA}$ & UNESP (Jaboticabal/SP) & Sudeste \\
\hline $\begin{array}{l}\text { Práticas em ecologia } \\
\text { humana; ecologia humana; } \\
\text { etnoecologia }\end{array}$ & G,PG & Ecologia & $\mathrm{CB}$ & UFRJ & Sudeste \\
\hline $\begin{array}{l}\text { Plantas tóxicas e } \\
\text { medicinais; botânica } \\
\text { aplicada à farmácia I }\end{array}$ & $\mathrm{G}$ & Biologia & $\mathrm{CB}$ & $\mathrm{UFJF}(\mathrm{MG})$ & Sudeste \\
\hline $\begin{array}{l}\text { Botânica econômica; } \\
\text { farmacobotânica }\end{array}$ & $\mathrm{G}$ & Biologia & $\mathrm{CB}$ & $\mathrm{UFOP}(\mathrm{MG})$ & Sudeste \\
\hline Botânica & G & Farmácia & $\mathrm{CF}$ & $\operatorname{EMESCAM}(\mathrm{ES})$ & Sudeste \\
\hline $\begin{array}{l}\text { Morfologia e taxonomia } \\
\text { de plantas avasculares } \\
\text { e vasculares }\end{array}$ & G & Biologia & $\mathrm{CB}$ & FAESA(ES) & Sudeste \\
\hline $\begin{array}{l}\text { Farmacognosia; } \\
\text { tecnologia de fitoterápicos }\end{array}$ & G & Farmácia & CF & UEM & Sul \\
\hline Horticultura aplicada & $\mathrm{G}$ & Agronomia & $\mathrm{CA}$ & UFSC & Sul \\
\hline $\begin{array}{l}\text { Botânica econômica; } \\
\text { plantas medicinais e } \\
\text { tóxicas; farmacologia }\end{array}$ & G & Biologia & $\mathrm{CB}$ & UFRGS & Sul \\
\hline $\begin{array}{r}\text { Etnofarmacologia; } \\
\text { botânica aplicada }\end{array}$ & PG & Farmácia & CF & UFRGS & Sul \\
\hline
\end{tabular}

devido à diversidade cultural própria às diversas regiões brasileiras, os programas oferecem temas específicos. Por exemplo, na disciplina oferecida na Universidade Estadual de Feira de Santana (UEFS), é discutida a importância do conhecimento e interação das crenças e comportamentos, pelo fato da cultura afrobrasileira ser bastante representada em grupos sociais locais. Outro exemplo é a Universidade Federal do Maranhão, que ressaltaa importância do uso, manejo e potencial dos ecossistemas maranhenses em relação aos seus recursos naturais (particularmente os recursos vegetais), tanto no ensino de graduação quanto de pósgradu ação.

Os conteúdos programáticos das disciplinas e a evolução dos estudos em etnobotânica, embora sigam um eixo central semelhante, conseqüência das limitadas fontes de material bibliográfico, definem caminhos de aplicação do conhecimento segundo a realidade sócioambiental regional.
A bibliografia referenciada nos programas das disciplinas de etnobotânica apresenta, portanto, similaridade, por serem de poucas fontes e em geral manuais estrangeiros. Esta realidade, contudo, começa a mudar, a partir de algumas publicações relacionadas a técnicas e métodos de pesquisa em etnobotânica no Brasil, com caráter didático, tais como Amorozo et al. (2002) e Albuquerque \& Lucena (2004).

As Regiões Norte e Centro-Oeste, com biomas considerados de alta diversidade vegetal e cultural como Amazônia e Cerrado apresentaram menor número de instituições de ensino que abordam a etnobotânica. Tal fato revela a necessidade da implementação de cursos e programas para o desenvolvimento desta disciplina nestes locais. A Universidade Federal do Pará possui o Núcleo de Altos Estudos Amazônicos que oferece doutorado em Desenvolvimento Su stentável do Trópico Úmido, bem como alguns cursos de especiali- 
zação com enfoque em populações tradicionais na Amazônia, direito ambiental e políticas públicas, com reconhecimento nacional e internacional. Embora não haja uma disciplina formal de etnobotânica, várias teses são desenvolvidas nesta área.

Ainda como resultado das entrevistas, junto aos docentes obtiveram-se, os seguintes itens considerados relevantes para o fortalecimento do ensino e pesquisa em etnobotânica:

1. Método: padronização e difusão da base teórica e metodologia de campo; incentivo à aplicação de métodos quantitativos; acesso facilitado à bibliografia específica para alunos e docentes; adaptação de técnicas de suficiência amostral.

2. Estímulo a docentes e alunos: capacitação e especialização na carreira acadêmica e de pesquisa; maior divulgação dos resultados de pesquisas na área em revistas nacionais e internacionais; maior credibilidade e compreensão da etnobotânica no meio acadêmico e científico; implementação da etnobotânica de forma sistematizada como disciplina específica nos cursos de graduação e pós-graduação.

3. Melhor comunicação e intercâmbio entre grupos de pesquisa.

4. Recursos financeiros: estímulo das agências de fomento para regulamentação da linha de etnobotânica dentro da pesquisa nacional.

\section{Considerações Finais}

Apesar da reconhecida importância da etnobotânica aplicada para a conservação e desenvolvimento sustentável, existem ainda deficiências como, falta de rigor no seu ensino e problemas relacionados ao desenvolvimento dos cursos ou programas, um quadro que no Brasil se assemelha com os demais países da América Latina. Dentre os principais problemas, inclui-se o desafio da interdisciplinaridade, com a necessidade da inserção de conceitos e métodos de outras disciplinas, uma ação ainda insuficientemente assimilada e pouco praticada pelos docentes brasileiros; desta forma precisa ser mais entendida na atualidade, em sua teoria e prática, pois deve deixar de carregar o estigma da falta de rigor metodológico existente até um passado recente. Os pré-requisitos no ensino da etnobotânica podem ainda criar resistência à disciplina, pelo seu caráter interdisciplinar, restringindo a sua oferta pela limitação de material didático, de equipes e de recursos materiais.

Considerando o tamanho da amostra e as condições do levantamento realizado, os resultados devem ser interpretados com cautela, sem que inferências ou conclusões sejam extraídas fora dos limites dos próprios dados usados. Entretanto, algumas tendências são claras nas informações obtidas. O levantamento, que acabou abrangendo em sua quase totalidade as universidades federais, registrou uma tendência positiva ao ensino da etnobotânica no Brasil, nos cursos de graduação e de pós-graduação, tanto ministrada formalmente como disciplina da grade curricular ou, como módulo disciplinar em outra disciplina formal. Mesmo nesta última situação, esta é ainda uma tendência de crescimento de importância, uma vez que os módulos de etnobotânica foram inseridos em disciplinas já existentes em áreas diversas.

Por outro lado, o crescente desenvolvimento e aperfeiçoamento das tecnologias utilizadas na coleta, isolamento, identificação e caracterização molecular dos recursos biológicos tem conduzido ao interesse por atividades de prospecção da diversidade biológica, na busca de novos produtos comerciais. Nesse contexto, a pesquisa em etnobotânica pode subsidiar estes novos esforços. Contudo, faz-se necessária a adequação da legislação nacional, de forma a contemplar os princípios da Convenção sobre Diversidade Biológica que visa a conservação pela utilização sustentável e a repartição justa e equiitativa dos benefícios derivados da utilização dos recursos naturais (MMA 2002). Estes tempos modernos que trazem novas 
demandas na área dos recursos naturais, certamente tornarão ainda mais clara a necessidade dos estudos em etnobotânica e, para tal, a importância do seu ensino formal nas universidades brasileiras.

A implementação e formalização da etnobotânica em cursos de graduação e pósgraduação no Brasil são imprescindíveis para o fortalecimento e difusão de trabalhos neste campo do saber. As dificuldades hoje encontradas relacionadas à elaboração de metodologias próprias e falta de pesquisadores nesta área serão, paulatinamente minimizadas e, como consequiência direta, haverá incremento gradual de profissionais qualificados para orientação formal de novos pesquisadores.

\section{Agradecimentos}

Os autores agradecem especialmente à Dra. Sonia Lagos-Witte (coordenadora do Grupo Etnobotánico Latinomericano - GELA) pelo apoio fundamental à realização deste trabalho; a todos aqueles que contribuíram com o fornecimento dos dados relativos às suas Instituições; ao World Wide Fund for Nature (WWF) e GELA pelo suporte financeiro ao primeiro autor. Agrademos ainda a contribuição do revisor pelas críticas e sugestões.

\section{REFERÊnCIaS Bibliográficas}

Albuquerque, U.P. de \& Lucena, R.F.P. de (Orgs.). 2004. Métodos e técnicas na pesquisa etnobotânica. Recife. Núcleo de Publicações em Ecologia e Etnobotânica Aplicada (NUPEEA), 189p.

Alcorn, J.B. 1995. The scope and aims of ethnobotany in a developing world. In: Schultes, R.E. \& Reis, S. von. (Eds.), Ethnobotany: evolution of a discipline. Dioscorides Press: Portland, Oregon, 23-39.

Alexiades, M.N. \& Sheldon J.W. (Eds.). 1996. Selected guidelines for ethnobotanical research: a field manual. The New York Botanical Garden Press. New York. Advances in Economic Botany 10: 1-306.
Alfaro, M. A. M. 1994. Estado actual de las investigaciones etnobotânicas en México. Bol. Soc. Bot. México 55: 65-74.

Amorozo, M. C. M; Ming, L. C. \& Silva, S. M. P. (Eds). 2002. Métodos de coleta e análise de dados em etnobiologia, etnoecologia e disciplinas correlatas. Anais do I Seminário de Etnobiologia e Etnoecologia do Sudeste. Rio Claro. 204p.

Balick, M. J. \& Cox., P. A. 1996. Plants, people and culture: the science of ethnobotany. Scientific American Library. New York. 228p.

Brasil. 1998. Ministério do Meio Ambiente, dos Recursos Hídricos e da Amazônia Legal. Primeiro relatório nacional para a conservação sobre diversidade biológica: Brasil. Brasília. 283p.

Diegues, A C. \& Arruda, R. S. V. (Org.). 2001. Saberes tradicionais e biodiversidade no Brasil. Brasília: Ministério do Meio Ambiente;São Paulo: USP. (Biodiversidade, 4). $175 \mathrm{p}$.

Ford, R. I. 1978. Ethnobotany: historical diversity and synthesis. In: R. I. Ford (Ed.), The nature and status of ethnobotany. Annals of Arnold Arboretum. Museum of Anthropology, University of Michigan, Michigan. Anthropological Papers 67: 33-49.

Fundação Coordenação de Aperfeiçoamento de Pessoal de Nível Superior (CAPES). 2003. Programas de PG reconhecidos. Disponível em: http://www.capes.gov.br/ cursos/ index.html. Acesso em: 13 de setembro de 2003.

Hamilton, A. C.; Shengji, J. P.; Kessy, J.; Khan, A. A.; Lagos-Witte, S. \& Shinwari, Z. K. 2003. The purposes and teaching of applied ethnobotany. People and Plants Working Paper 11. WWF, Godalming, UK. 72p.

IBGE - Instituto Brasileiro de Geografia e Estatística. 2001. Resultados do universo do censo 2000. Disponível em: http:// 
www.ibge.gov.br. Acesso em: $7 \mathrm{de}$ dezembro de 2001.

IBGE - Instituto Brasileiro de Geografia e Estatística. 2001. Resultados do universo do censo 2000. Disponível em: http:// www.ibge.gov.br. Acesso em: 7 de dezembro de 2001.

INEP - Instituto Nacional de Estudos e Pesquisas Educacionais Anísio Teixeira. 2003. Censo da Educação Superior. <http:/ /www.inep.gov.br/download/superior/ censo/2004/ResumoTecnico2003ANEXO. pdf. Acesso em: 02 de março de 2005.
Ministério da Educação (MEC). Secretária de Ensino Superior. 2003. Disponível em http:/ /www.mec.gov.br/sesu/fies/ies.shtm. Acesso em: 13 de setembro de 2003.

Ministério do Meio Ambiente (MMA). 2002. Biodiversidade brasileira: avaliação e identificação de áreas prioritárias para a conservação, utilização sustentável e repartição de benefícios da biodiversidade brasileira. Secretaria de Biodiversidade e Florestas. MMA, Brasília. 283p. 
